\title{
The feasibility of urethral plate preservation in proximal and mid-penile hypospadias: sequential and anatomical approach to the repair
}

\author{
Vivek Parameswara Sarma@
}

\begin{abstract}
Background: The assessment of a child having hypospadias with chordee/ventral curvature (VC) and meatal position that appears to be proximal/mid-penile can be challenging with regard to the choice of chordee correction and type of urethroplasty. The feasibility of preservation of native urethral plate is dependent on these choices. Classically, urethral plate resection of the corpora is performed to correct severe $V C$, whenever $V C$ is presumed to be due to short urethral plate. But VC is seen to persist in many such cases, in spite of this maneuver that commits the patient to a more complex reconstruction. The aim of the study was to analyze the variation in preoperative and intraoperative assessment of proximal and mid-penile hypospadias, with respect to severity and possible surgical options, in patients treated by a standard protocol of sequential and anatomical approach to repair. The other objective was to ascertain if "extensive ventral urethral detethering" (in all cases) and "urethral plate augmentation" (in select cases) could facilitate more anatomical repair in these cases, with urethral plate preservation and utilization for repair wherever feasible.

Results: Fifty-two children who underwent the specific protocol of repair during the 5-year period from January 2014 to December 2018 at a tertiary teaching institution were included in the study. The essential principles adopted for the surgery were as follows: (i) urethral plate preservation in all possible situations; (ii) "extensive ventral urethral detethering" up to the bulb, as a preliminary step, (iii) sequential correction of VC with urethral plate augmentation (in select cases); and (iv) selecting the optimal repair based on the following principles: (a) urethral plate tubularization, (b) urethral plate augmentation, and (c) urethral plate substitution. There was considerable difference in the preoperative and intraoperative assessment of meatal position, with 12 of the apparently mid-penile hypospadias being reclassified as distal penile after preliminary dissection. Three of the penoscrotal variants were regrouped as proximal penile and 6 of the proximal penile were regrouped as mid-penile type. Majority of cases which were deemed to require complex reconstruction on preoperative assessment could be treated by a single-stage procedure.

Conclusion: The meatal position is seen to shift distally in select cases of proximal or mid-penile hypospadias after thorough degloving, dartos release, and detethering of Buck's fascia over ventral urethra. Urethral plate can be preserved for utilization in repair in many of these cases by augmenting the urethral plate, enabling a more anatomical neourethral reconstruction. Resection of urethral plate can be thus restricted to the most severe cases of VC.
\end{abstract}

Keywords: Hypospadias, Urethral plate, Chordee, Ventral curvature, Urethroplasty, Buck's fascia

Correspondence: vivsarma@gmail.com

Department of Paediatric Surgery, SAT Hospital, Government Medical

College, Thiruvananthapuram, Kerala, India

() The Author(s). 2020 Open Access This article is licensed under a Creative Commons Attribution 4.0 International License, which permits use, sharing, adaptation, distribution and reproduction in any medium or format, as long as you give appropriate credit to the original author(s) and the source, provide a link to the Creative Commons licence, and indicate if changes were made. The images or other third party material in this article are included in the article's Creative Commons licence, unless indicated otherwise in a credit line to the material. If material is not included in the article's Creative Commons licence and your intended use is not permitted by statutory regulation or exceeds the permitted use, you will need to obtain permission directly from the copyright holder. To view a copy of this licence, visit http://creativecommons.org/licenses/by/4.0/. 


\section{Background}

The clinical assessment and intraoperative decisionmaking in hypospadias surgery are extremely vital. Even a well performed operation can fail to achieve the desired objectives if the procedure is not apt for the patient. The decision regarding the type of repair suitable for the patient should be made after considering a multitude of factors, failing which an optimal result will be elusive. The assessment of a child having hypospadias with chordee/ventral curvature (VC) and meatal position that appears to be proximal/mid-penile can be challenging with regard to the choice of chordee correction and type of urethroplasty. The feasibility of preservation of native urethral plate is dependent on these choices. Classically, urethral plate resection of the corpora is performed to correct severe $\mathrm{VC}$, whenever $\mathrm{VC}$ is presumed to be due to short urethral plate. But VC is seen to persist in many such cases. The early resection of urethral plate commits the surgeon to a more complex reconstruction, especially using non-native tissue, along with the risk of attendant complications.

\section{Objectives}

The aim of the study was to analyze the variation in preoperative and intraoperative assessment of proximal and mid-penile hypospadias, with respect to severity and possible surgical options, in patients treated by a standard protocol of sequential and anatomical approach to repair. The other objective was to ascertain if extensive ventral urethral detethering (in all cases) and urethral plate augmentation (in select cases) could facilitate more anatomical repair in these cases, with urethral plate preservation and utilization for repair, wherever feasible.

\section{Methods}

A combined retrospective and prospective analysis of children operated during the 5-year period from January 2014 to December 2018 was done for the study. The cases with preoperative diagnosis of mid-penile/proximal penile/penoscrotal hypospadias only were included in the analysis. In the past, a significant proportion of these patients would have been treated by staged correction after urethral plate resection, based on preoperative assessment. All the cases were operated by a single surgeon. Exclusion criteria were as follows: (1) distal penile hypospadias, (2) perineal hypospadias, (3) previous hypospadias surgery (reoperative cases), (4) severe pre-penile scrotum, and (5) disorders of sexual differentiation. The preoperative, intraoperative, and postoperative follow-up records of all patients who underwent the specific protocol of repair were studied in detail to analyze the cardinal observations in decision-making and results. The preoperative assessment of type, severity, and suitable procedure were compared with the intraoperative assessment. The postoperative outcome was reviewed in detail. Ethics approval and standard informed consent were obtained as per institutional protocol.

In preoperative assessment, the factors considered were as follows: (1) meatal position, (2) severity of VC (mild/moderate/severe), (3) the possible maneuver required for correction of VC (degloving and detethering/ auxiliary procedures like midline dorsal plication/urethral plate resection/ventral corporotomies), (4) size of phallus, (5) quality and width of urethral plate, (6) glandular groove and glans width, (7) associated issues like pre-penile scrotum/undescended testes, and (8) type of procedure likely to be required (urethral plate tubularization/augmentation/substitution). These were essentially noted for comparison with the intraoperative observations including meatal position after correction of $\mathrm{VC}$, final mode of correction of $\mathrm{VC}$, and type of urethroplasty done. The definitive observations and final decisions regarding the severity of hypospadias and ideal operative procedure were made only intraoperatively.

The algorithm followed for hypospadias repair in the present series is summarized in Fig. 1. Intraoperatively, a sequential and anatomical approach to repair was adopted. After catheterization and marking the incision, the initial step was a circumferential incision (circumcoronal), which was carried proximal to the meatus by a U-shaped extension near the meatus in all cases. Even in apparently proximal hypospadias, the incision was not carried distal to the meatus. The initial dissection on the ventral surface of urethra close to the meatus to separate the native urethra from overlying thin skin was tedious, but became easier as the dissection proceeded proximally. This was essentially aimed at preserving the urethral plate and native urethra, in all but the most severe instances of $\mathrm{VC}$, or preserves the plate in other cases, till such a stage were all other options to correct VC had been exhausted [1-3].

The next step was thorough degloving of the phallus till base with release of phallic and scrotal Dartos, as classically described. This was combined with "extensive ventral urethral detethering" of the deeper Buck's fascia surrounding the urethra and aborted corpus spongiosum. The dissection was neither circumferential, nor it lifted the urethra from the corpora, but extended to free the ventral surface of urethra till the bulb. Though similar dissection has been previously described as an ancillary maneuver to correct severe $\mathrm{VC}$, it has been employed in the present series as a basic, mandatory, and preliminary step $[4,5]$ The phallus being tethered to scrotum is a common observation in proximal hypospadias or severe VC (referred to here as penoscrotal fusion). After the thorough degloving, dartos release, and detethering of ventral urethra (the 3Ds of preliminary dissection in hypospadias), the normal relation between 


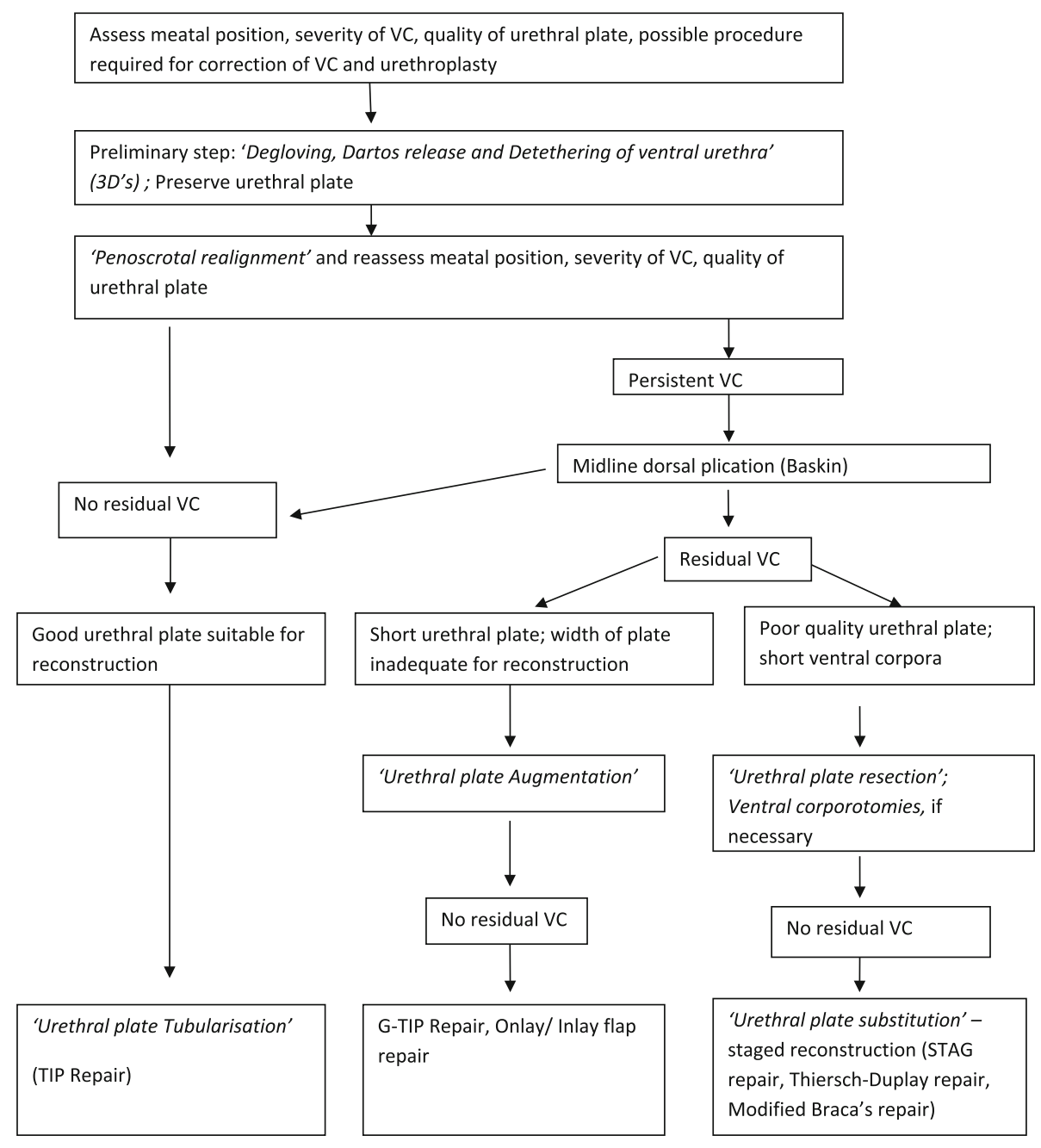

Acronyms used: VC: Ventral curvature; TIP: Tubularised Incised Plate Urethroplasty; G-TIP: Grafted TIP; STAG: Staged tubularised autograft of prepucial mucosa

Fig. 1 Algorithm followed for proximal/mid-penile hypospadias repair in the present series. VC ventral curvature, TIP tubularized incised plate urethroplasty, G-TIP grafted TIP, STAG staged tubularized autograft of prepucial mucosa

penis and scrotum was observed to be restored. This has been referred to here as penoscrotal realignment (Figs. 2 and 3). The final position of meatus in relation to the phallus, severity of $\mathrm{VC}$, the suitability of urethral plate for use in reconstruction, and the optimal method for creation of neourethra/necessity for a staged procedure were assessed at this stage. The hypospadias was reclassified based on the meatal position in relation to the glans and base of the penis. If the meatal position was in the distal third, mid-third, proximal-third, and penoscrotal junction, the hypospadias was reclassified as distal penile, mid-penile, proximal penile, and penoscrotal types respectively.

$\mathrm{VC}$ was reassessed afterwards by artificial erection (classical Gittes test) and if seen to persist, midline dorsal plication (Baskin) was performed. The patients with persistent VC after midline dorsal plication were classified as those suitable for urethral plate augmentation or those requiring urethral plate resection and substitution. Urethral plate augmentation was started by a single Z-plasty incision on the urethral plate at the site of maximum $\mathrm{VC}$, to divide the short urethral plate, preserving the vascular plexus deep to the urethral plate (Fig. 4). This is supplemented by an onlay flap of inner prepuce. The incision was made to divide the urethral plate and combined with midline dorsal plication to correct VC. It is used along with the classical midline incision for tubularization, where necessary. Severe VC associated with poor urethral plate or short ventral corpora required urethral plate resection. This was combined with ventral corporotomies and midline dorsal plication wherever necessary. The adequate and complete correction of $\mathrm{VC}$ was given paramount importance. Urethral plate resection has been employed as the 


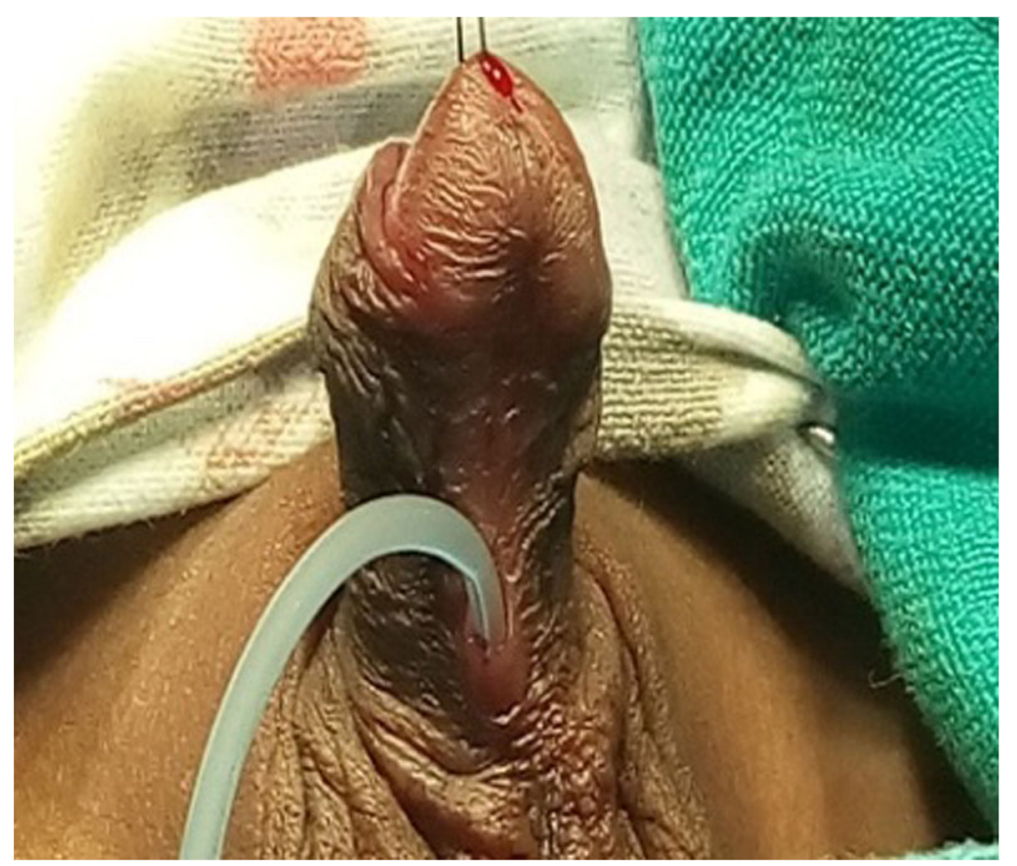

Fig. 2 Preoperative picture of proximal hypospadias with ventral curvature

last resort to correct VC in the present series. The construction of neourethra is based on the one of the following principles:

(A) Urethral plate tubularization: if there was no residual VC and urethral plate was adequate, a single-stage urethroplasty is done [classical tubularized incised plate (TIP) urethroplasty] [6]. A modification employed in select cases was to "stagger" one lateral incision of the urethral plate more laterally and to create unequal sections of urethral plate, but with total caliber more than 3 times that of the catheter used. The suture line of reconstruction of the neourethra was thus taken away from the midline on ventral surface, to lie more laterally and closer to the dorsum. (B) Urethral plate augmentation: inadequate length and width of an otherwise sufficient urethral plate was overcome by a Z-plasty incision on the plate, along with a graft to augment the plate (GTIP/grafted TIP repair) [7]. The use of urethral plate division along with onlay (or inlay) flaps helps to utilize the available urethral plate, in cases with feasibility of a single-stage reconstruction of neourethra. The preferred method in this series was the use of an onlay flap of pedicled inner prepuce, wherever native urethral plate was deemed inadequate for tubularization, but did not require resection. (C) Urethral plate substitution: if urethral plate resection was deemed necessary, the surgical options preferred were staged Braca's procedure (using a pedicled inner prepucial flap as a graft to substitute the urethral plate), the classical Thiersch-Duplay procedure (with first stage transfer of Byar's flaps of prepucial skin), or STAG repair (staged tubularized autograft, with tubularization of neourethral plate of prepucial autograft) [810]. In cases requiring urethral plate substitution, twostage procedures using native tissue or pedicled local graft were always preferred to complex reconstruction using non-native tissue or free grafts.

The divergent corpus spongiosum was mobilized and approximated in the midline over the neourethra whenever feasible. The most commonly used cover for the reconstructed neourethra was the pedicled inner prepucial flap. The other options used for cover were corpus spongiosum, local dartos flap and tunica vaginalis flap. The pedicled tunica vaginalis flap was used liberally even in primary hypospadias repair, especially for proximal and mid-penile hypospadias with severe $\mathrm{VC}$, where judicious use of prepucial skin to cover the ventral surface was necessary. A $6 \mathrm{Fr} / 8 \mathrm{Fr}$ Silicone Foley's catheter was used for urinary drainage for 7-10 days postoperatively. Urethral calibration with a small metal dilator was started 2 weeks postoperatively.

\section{Results}

The records of 52 children (24 retrospective and 28 prospective cases) operated during the 5 -year period from January 2014 to December 2018 were analyzed for the study. Only the results of the primary surgery (single/ two stage) were assessed and the results of reoperative surgery for complications were not assessed. The results of the analysis are summarized in Tables $1,2,3,4,5,6$, $7,8,9$, and 10. A higher proportion of older children 


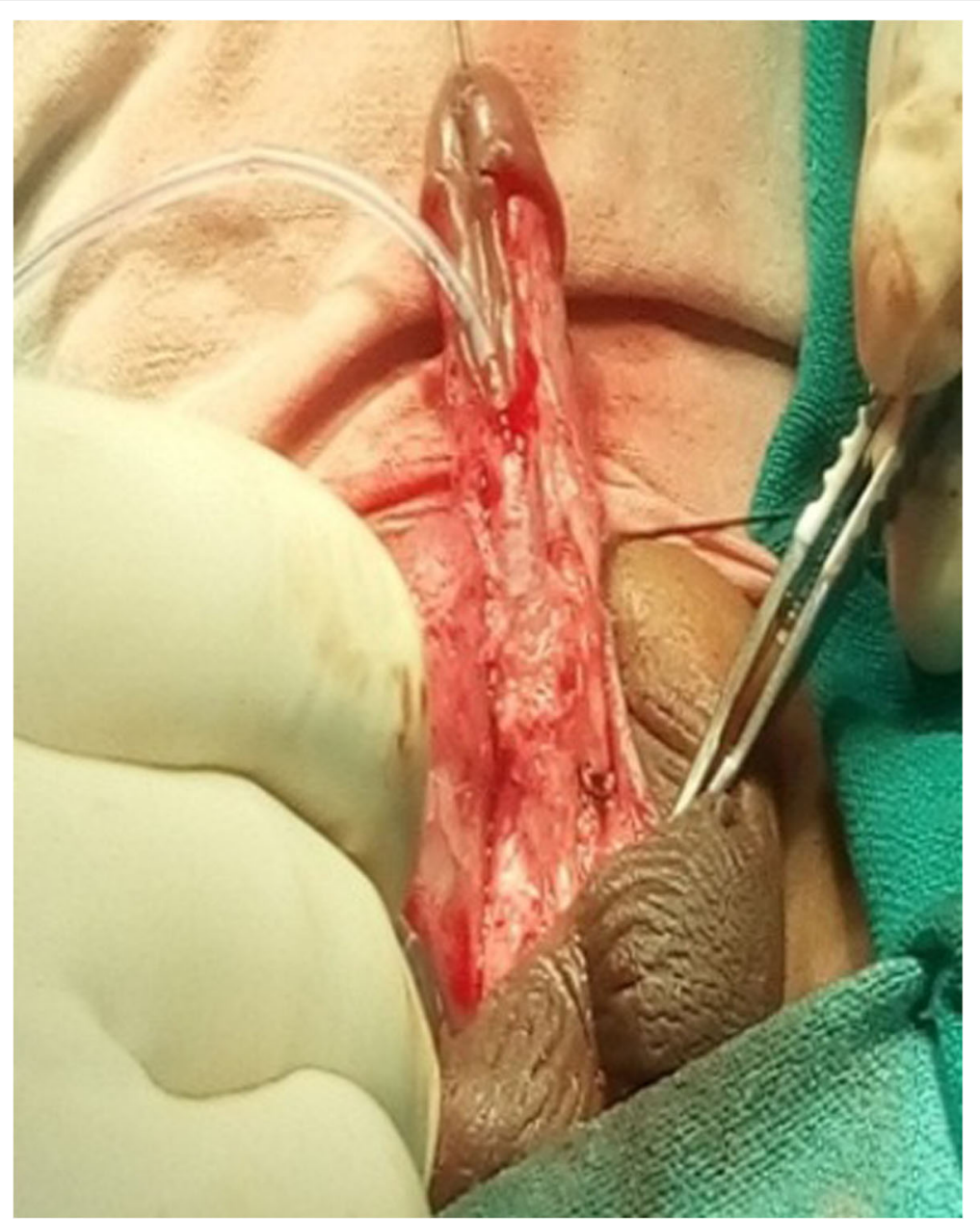

Fig. 3 Intraoperative picture of the same patient as in Fig. 2, after extensive ventral urethral detethering and penoscrotal realignment

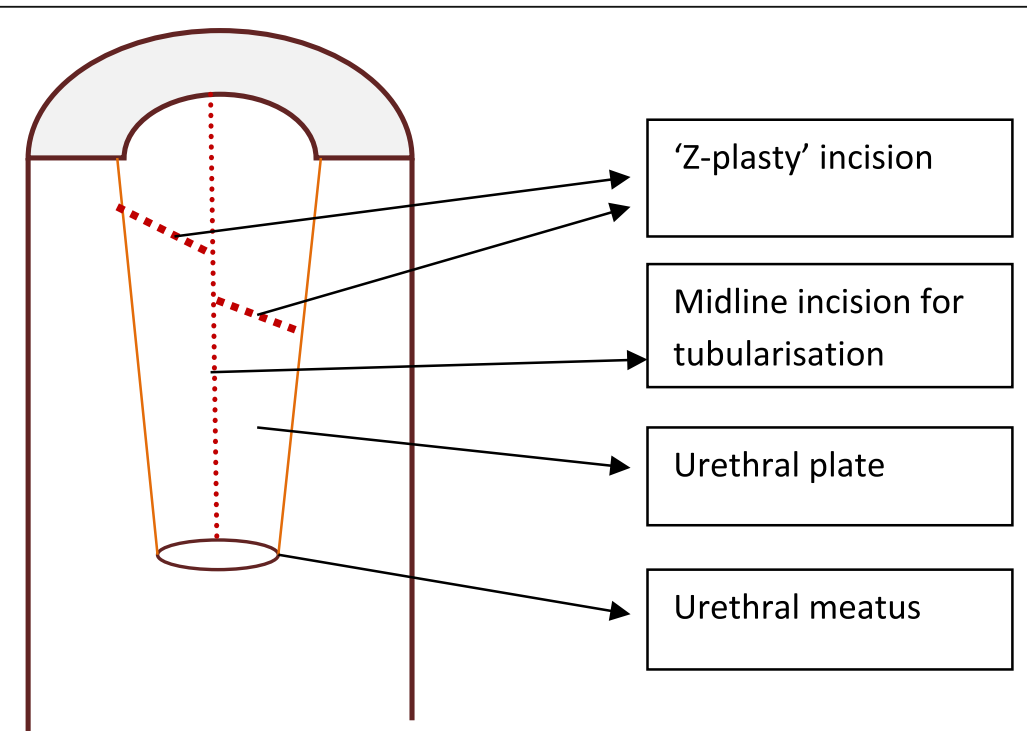

Fig. 4 Schematic representation of the Z-plasty incision, given along with the midline vertical incision, for a short urethral plate 
Table 1 Age of the patients at surgery

\begin{tabular}{ll}
\hline Age of the patient at surgery & Number of cases $(\boldsymbol{n}=52)$ \\
\hline Less than 1 year & $8(15 \%)$ \\
1 to 2 years & $24(46 \%)$ \\
2 to 5 years & $13(25 \%)$ \\
5 to 10 years & $7(13 \%)$ \\
\hline
\end{tabular}

were noted in the study, mainly due to delay in presentation. The most common age at operation was 1-2 years (Table 1). There was considerable difference in the preoperative assessment and intraoperative assessment of meatal position, with 12 of the apparently mid-penile hypospadias being reclassified as distal penile after sequential correction. Three of the penoscrotal variants were regrouped as proximal penile and 6 of the proximal penile were regrouped as mid-penile type (Table 2). It was observed that a major percentage of patients who were deemed to require urethral plate augmentation/ substitution could undergo urethral plate tubularization after the intraoperative reassessment (Table 3). In contrast to the preoperative assessment, only fewer patients required urethral plate resection to correct VC. Auxiliary procedures to correct $\mathrm{VC}$ were also required in fewer cases. VC could be corrected by thorough degloving and extensive ventral urethral detethering in large proportion of cases (Tables 4 and 5).

The preferred method for urethral plate augmentation was an "onlay" flap of inner prepucial layer. Urethral plate substitution was done by the classical staged Thiersch-Duplay procedure or modified staged Braca's procedure/the STAG repair, with transfer of inner prepucial flap to substitute the urethral plate in the first stage and tubularization of this layer as the second stage [11-13]. These procedures (9/52) were performed as staged surgeries. It is notable that a significant number (43/52) of these patients could undergo a single-stage reconstruction (Table 6). There was a relatively high proportion of use of tunica vaginalis flap for neourethral cover, especially in proximal hypospadias, in an effort to preserve prepucial skin flaps (Table 7). The early postoperative period was relatively uneventful in majority of the patients, except for minor complications. Only major issues of wound dehiscence and urinary leak/fistula

Table 2 Variation in the preoperative and intraoperative assessment of hypospadias after sequential correction

\begin{tabular}{lll}
\hline Type of hypospadias & $\begin{array}{l}\text { Preoperative } \\
\text { assessment }(\boldsymbol{n}=52)\end{array}$ & $\begin{array}{l}\text { Intraoperative } \\
\text { reassessment }(\boldsymbol{n}=52)\end{array}$ \\
\hline Distal penile & - & $12(23 \%)$ \\
Mid-penile & $25(48 \%)$ & $19(37 \%)$ \\
Proximal penile & $17(33 \%)$ & $14(27 \%)$ \\
Penoscrotal & $10(19 \%)$ & $7(13 \%)$ \\
\hline
\end{tabular}

Table 3 Assessment of procedure required for urethroplasty: variation between preoperative and intraoperative assessment

\begin{tabular}{lll}
\hline $\begin{array}{l}\text { Assessment of procedure } \\
\text { required }\end{array}$ & $\begin{array}{l}\text { Preoperative } \\
\text { assessment } \\
(\boldsymbol{n}=52)\end{array}$ & $\begin{array}{l}\text { Intraoperative } \\
\text { reassessment } \\
(\boldsymbol{n}=52)\end{array}$ \\
\hline $\begin{array}{l}\text { Suitable for urethral plate } \\
\text { tubularization }\end{array}$ & $14(27 \%)$ & $28(54 \%)$ \\
$\begin{array}{l}\text { Needs urethral plate } \\
\text { augmentation }\end{array}$ & $23(44 \%)$ & $15(29 \%)$ \\
$\begin{array}{l}\text { Staged reconstruction with } \\
\text { urethral plate substitution }\end{array}$ & $15(29 \%)$ & $9(17 \%)$ \\
\hline
\end{tabular}

occurred in 2 cases that underwent an onlay flap reconstruction (Table 8). The functional and cosmetic outcome was satisfactory in majority of the cases. The available period of follow-up varied from a minimum of 6 months to maximum of 3 years. The mean period of follow-up available was 15 months. Complications during follow-up included meatal stenosis, glans dehiscence, urethrocutaneous fistula, prepucial dehiscence, residual $\mathrm{VC}$, stenosis of neourethra, and complete dehiscence of repair. Many of the complications occurred early in the series (Table 9). Only 2 children with persistent meatal stenosis required meatotomy. Four children underwent closure of urethral fistula and 3 underwent reoperative procedure for wound dehiscence/residual VC, while one child underwent a G-TIP procedure and had complete dehiscence of repair, and later required reoperation (onlay flap) (Table 10).

\section{Discussion}

Many children with an "apparently" proximal hypospadias undergo division of urethral plate (even with good quality plate), staged urethroplasty (necessitated by resection of the urethral plate), and complex reconstruction, with long neourethra. The present trend advocates the performance of complex, staged repairs using nonnative tissue in many cases, in the context of proximal hypospadias and severe chordee. Urethral plate resection of the corpora is being employed liberally as an adjunct to correct VC $[14,15]$. The disadvantages of this approach are as follows: (1) the meatal position is usually seen to shift more "proximally" after correction of VC by resection of urethral plate, necessitating a complicated

Table 4 Assessment of chordee based on preoperative assessment and intraoperative reassessment

\begin{tabular}{lll}
\hline Assessment of VC & $\begin{array}{l}\text { Preoperative } \\
(\boldsymbol{n}=52)\end{array}$ & $\begin{array}{l}\text { Intraoperative } \\
(\boldsymbol{n}=52)\end{array}$ \\
\hline $\begin{array}{l}\text { Mild-VC can be corrected by } \\
\text { degloving and detethering only }\end{array}$ & $18(35 \%)$ & $30(58 \%)$ \\
$\begin{array}{l}\text { Moderate—needs auxillary procedures } \\
\text { to correct VC }\end{array}$ & $19(37 \%)$ & $13(25 \%)$ \\
$\begin{array}{l}\text { Severe-needs urethral plate transection } \\
15(29 \%)\end{array}$ & $9(17 \%)$ \\
\hline
\end{tabular}


Table $\mathbf{5}$ The auxillary procedures employed to correct VC after degloving and detethering

\begin{tabular}{ll}
\hline Auxillary procedures to correct VC & $n=13$ \\
\hline Midline dorsal plication & $9(69 \%)$ \\
Ventral corporotomies & $3(23 \%)$ \\
Dermal graft & $1(8 \%)$ \\
\hline
\end{tabular}

repair; (2) it does not necessarily correct VC in all cases; (3) it may involve sacrifice of an utilizable urethral plate; (4) commits the patient to a more complex reconstruction that is prone to complications; (5) use of non-native tissue for repair; and (6) such neourethra is likely to be non-anatomical and superficially sited. These considerations highlight the fact that urethral plate resection should only be employed judiciously in hypospadias repair.

The native urethral plate consists of surface epithelium overlying well-vascularized connective tissue which can be preserved for urethroplasty. It is unusual to find a urethral plate that is totally dysplastic or unsuitable for reconstruction. It has also been conclusively demonstrated that VC is actually related to shortened ventral shaft skin, dartos, corpus spongiosum, and/or corpora cavernosa than due to any "chordee structure" distal to the meatus. Therefore, curvature that persists after extensive dissection of these tissues is corrected by either dorsal plication or ventral corporal incision and grafting, depending on severity. Warwick has reported bulbar urethral mobilization as an adjunct during hypospadias surgery $[1,3,4,10,16]$. Stricture urethroplasty also entails extensive mobilization of the urethra. The similar principle of bulbar urethral mobilization, though not circumferential, is adopted in this series for "extensive ventral urethral detethering." The basic principle of this maneuver is based on the normal anatomical configuration of Buck's fascia splitting to surround the corpus spongiosum, which encloses the urethra [16]. In a hypospadiac phallus, the spongiosum is deficient, but Buck's fascia tethers the urethra. Release of this tethering Buck's fascia, in addition to the superficial dartos release, aids in correction of VC. This enables native urethra to lie in a more anatomical position in relation to phallus.

Table 6 Type of final procedure (urethroplasty) performed

\begin{tabular}{ll}
\hline Type of final procedure performed & $n=52$ \\
\hline Classical TIP urethroplasty (Snodgrass procedure) & $28(54 \%)$ \\
G-TIP procedure & $2(4 \%)$ \\
Onlay flaps for urethral plate augmentation & $13(25 \%)$ \\
$\begin{array}{l}\text { Modified Braca procedure/ "STAG" repair with } \\
\text { inner-prepucial flap (staged) }\end{array}$ & $5(10 \%)$ \\
Thiersch-Duplay procedure & $4(8 \%)$ \\
\hline
\end{tabular}

Table 7 Type of neourethral cover used after urethroplasty

\begin{tabular}{ll}
\hline Type of neourethral cover used & $n=52$ \\
\hline Inner prepucial flap & $32(62 \%)$ \\
Local dartos flap & $6(12 \%)$ \\
Tunica vaginalis flap & $14(26 \%)$ \\
\hline
\end{tabular}

It has been described that $\mathrm{VC}>30^{\circ}$ that persists even after urethral plate resection and its release from the corpora is ideally corrected by ventral corporotomies with a supplemental midline dorsal plication if necessary $[16,17]$. This raises the question whether the initial urethral plate resection has helped these patients. These patients, with the possibility of short length of urethra being the reason for $\mathrm{VC}$, were seen to benefit from $u r$ ethral plate augmentation. The essential concept was to divide the urethral plate horizontally by a single " $\mathrm{Z}$ plasty" incision (in addition to the midline relaxing incision of TIP), preserving the vascular plexus underneath the plate, to overcome the deficiency in length of the urethral plate. This is supplemented ventrally by an onlay flap. The incision itself is expected to heal by epithelial growth just like a midline relaxing incision. The incision on the urethral plate along with the dorsal plication facilitates correction of $\mathrm{VC}$ in good number of cases, avoiding urethral plate resection.

The Glans-Urethral Meatus-Shaft (GMS) score has been described as a concise and reproducible way to describe hypospadias severity [18]. Also, the importance of intraoperative determination of hypospadias severity is now considered to be standard practice $[19,20]$. In this study, an attempt has been done to analyze the difference between preoperative and intraoperative assessment of hypospadias and feasibility of urethral plate preservation in certain instances, where urethral plate resection is otherwise deemed necessary. The following observations formed the cornerstone of this approach: (1) the severe varieties of hypospadias are usually associated with a high riding scrotum, which has been referred to here as penoscrotal fusion (which could be considered as a milder type of pre-penile scrotum). This complicates the judgment of actual meatal position on the phallus and severity of VC. The meatal position in hypospadias should be judged only intraoperatively after "Penoscrotal

Table 8 Early complications after surgery (at or before 2 weeks postoperatively)

\begin{tabular}{ll}
\hline Early complications (<2 weeks) & $n=52$ \\
\hline Catheter dislodgement/blockage & $2(4 \%)$ \\
Bleeding/hematoma & $4(8 \%)$ \\
Wound dehiscence & $2(4 \%)$ \\
Urinary leak/fistula & $2(4 \%)$ \\
Superficial prepucial skin necrosis & $2(4 \%)$ \\
\hline
\end{tabular}


Table 9 Delayed complications after surgery (after 2 weeks postoperatively)

\begin{tabular}{ll}
\hline Delayed complications (after 2 weeks) & $n=52$ \\
\hline Meatal stenosis & $4(8 \%)$ \\
Glans dehiscence & $2(4 \%)$ \\
Urethrocutaneous fistula & $4(8 \%)$ \\
Preputial dehiscence & $1(2 \%)$ \\
Residual VC & $1(2 \%)$ \\
Stenosis of neourethra & $2(4 \%)$ \\
Complete dehiscence of repair & $1(2 \%)$ \\
\hline
\end{tabular}

realignment." (2) The cause of VC is more significantly due to abnormalities proximal to the meatus than those distal to the meatus. Hence, extensive proximal dissection can free the phallic urethra and restore the normal relation of urethra to the phallus and of the phallus to the scrotum. Better assessment of meatal position and $\mathrm{VC}$ is possible after this maneuver. (3) Degloving, dartos release, and detethering (3Ds) along with midline dorsal plication, where necessary, will correct the $\mathrm{VC}$ in a significant proportion of cases, where $\mathrm{VC}$ is due to short ventral shaft skin and contracted dartos and Buck's fascia. The importance of release of the tethering Buck's fascia encircling the native urethra is a critical aspect in this approach, and this enables better assessment of residual VC. It is important to note that all surgical options for correction of $\mathrm{VC}$ and urethroplasty are still open after this maneuver. (4) Urethral plate is generally suitable for being incorporated in repair in many of these cases by the principles of tubularization/augmentation. This would facilitate a more anatomical repair with lesser risk of complications. (5) Urethral plate resection and substitution should be necessary only in select cases, after other abnormalities responsible for $\mathrm{VC}$ have been addressed. In such cases that require urethral plate substitution, staged procedures, with preliminary transfer of robust local flaps and secondary tubularization, have been preferred in this series, to single-stage surgery or more complex reconstruction.

The drawbacks of this study include subjective nature of assessment of $\mathrm{VC}$ in the absence of measurement

Table 10 Need for additional procedures after surgery

\begin{tabular}{ll}
\hline Need for additional procedures & $n=52$ \\
\hline Suprapubic cystostomy & $2(4 \%)$ \\
Meatotomy/meatoplasty & $2(4 \%)$ \\
Fistula closure & $4(8 \%)$ \\
Reoperative procedure for residual VC & $1(2 \%)$ \\
Redo repair: partial & $2(4 \%)$ \\
Redo urethroplasty: complete & $1(2 \%)$ \\
\hline
\end{tabular}

with a goniometer, possibility of observer bias, relatively short period of follow-up to assess long-term problems like recurrent chordee and the unproven nature of healing of urethral plate division. Also, statistical analysis of significance of the observations could not be done because of the multiple variables in patient and disease factors, which merit a larger randomized study.

\section{Conclusion}

The meatal position is seen to shift distally in select cases of proximal or mid-penile hypospadias after thorough degloving, dartos release, and detethering of Buck's fascia over ventral urethra. Urethral plate can be preserved for utilization in repair in many of these cases by augmenting the urethral plate, enabling a more anatomical neourethral reconstruction. Resection of urethral plate can be thus restricted to the most severe cases of VC.

\section{Abbreviations}

VC: Ventral Curvature; TIP: Tubularized incised plate (urethroplasty);

STAG: Staged tubularized autograft; GMS: Glans-Urethral Meatus-Shaft (score)

\section{Acknowledgements}

The sincere cooperation of all the faculty and residents in the department who contributed to the care of the patients is gratefully acknowledged.

\section{Author's contributions}

The conceptualization, data collection, data analysis, and final compilation of the article have been done by the author himself.

\section{Funding}

No funding was procured for this study.

\section{Availability of data and materials}

Available upon request.

\section{Ethics approval and consent to participate}

This article does not contain any studies with human participants or animals performed by the author. The study involved only chart review and analysis of routine preoperative, intraoperative, postoperative, and follow-up data of a standard surgical procedure, for which necessary institutional approval has been obtained. Standard institutional informed consent was obtained from all cases included in the study.

\section{Consent for publication}

The author gives consent for publication.

\section{Competing interests}

The author declares that there are no competing interests.

Received: 26 May 2020 Accepted: 13 July 2020

Published online: 03 September 2020

\footnotetext{
References

1. Snodgrass W, Patterson K, Plaire JC, Grady R, Mitchell ME. Histology of the urethral plate: implications for hypospadias repair. J Urol. 2000;164:988-90.

2. Snodgrass W. Tubularized, incised plate urethroplasty for distal hypospadias. J Urol. 1994;151:464-5.

3. Snodgrass W, Koyle M, Manzoni G, Hurwitz R, Caldamone A, Ehrlich R. Tubularized incised plate hypospadias repair for proximal hypospadias. J Urol. 1998;159:2129-31.

4. Warwick RT, Parkhouse H, Chapple CR. Bulbar elongation anastomotic meatoplasty (BEAM) for subterminal and hypospadiac urethroplasty. J Urol. 1997;158:1160-7.
} 
5. Bhat A, Abrol N, Saxena G, et al. Tubularised incise plate urethroplasty in severe hypospadias: A variant of technique. First World Congress on Hypospadias and Intersex Disorders. Istanbul: In; 2005.

6. Snodgrass W, Yucel S. Tubularized incised plate for mid shaft and proximal hypospadias repair. J Urol. 2007;177:698-702.

7. Kolon TF, Gonzales ET Jr. The dorsal inlay graft for hypospadias repair. J Urol. 2000;163(6):1941-3.

8. Bracka A. Hypospadias repair: the two-stage alternative. British Journal of Urology. 1995;76:31-41.

9. Castagnetti M, El-Ghoneimi A. Surgical management of primary severe hypospadias in children: systematic 20-year review. J Urol (2010) 184:14697410.1016/j.juro.2010.06.044.

10. Nguyen MT, Snodgrass WT. Zaontz. Effect of urethral plate characteristics on tubularized incised plate urethroplasty. J Urol. 2004;171:1260-2.

11. Braga LH, Lorenzo AJ, Salle JL. Tubularized incised plate urethroplasty for distal hypospadias: a literature review. Indian J Urol (2008) 24:219-2510. 4103/0970-1591.40619.

12. Dutta HK. Meatal and corpus spongiosum advancement: a better technique for distal hypospadias repair. Pediatr Surg Int (2013) 29:633-810.1007/ s00383-013-3292-x.

13. Snodgrass WT, Granberg C, Bush NC. Urethral strictures following urethral plate and proximal urethral elevation during proximal TIP hypospadias repair. J Pediatr Urol(2013) 9(Pt B):990-410.1016/j.jpurol.2013.04.005.

14. Singh RB, Pavithran NM. Lessons learnt from Snodgrass tip urethroplasty: A study of 75 cases. Pediatr Surg Int. 2004;20:204-6.

15. Stehr M, Lehner M, Schuster T, Heinrich M, Dietz HG. Tubularized incised plate (TIP) urethroplasty (Snodgrass) in primary hypospadias repair. Eur J Pediatr Surg. 2005;15:420-4

16. Baskin LS, Erol A, Li YW, Cunha GR. Anatomical studies of hypospadias. J Urol. 1998;160(3 Pt 2):1108-37.

17. Luo CC, Lin JN. Repair of hypospadias complications using the tubularized, incised plate urethroplasty. J Pediatr Surg. 1999;34:1665-7.

18. Arlen, Angela M. et al. Further analysis of the Glans-Urethral Meatus-Shaft (GMS) hypospadias score: Correlation with postoperative complications Arlen, Angela M. et al. Journal of Pediatric Urology, Volume 11, Issue 2, 71. e1 - 71.e5.

19. Mane S, Arlikar J, Dhende N. Modified tubularized incised plate urethroplasty. J Indian Assoc Pediatr Surg (2013) 18:62-510.4103/0971-9261. 109354.

20. Cook A, Khoury AE, Neville C, Bagli DJ, Farhat WA, Pippi Salle JL. A multicenter evaluation of technical preferences for primary hypospadias repair. J Urol. 2005;174:2354-7.

\section{Publisher's Note}

Springer Nature remains neutral with regard to jurisdictional claims in published maps and institutional affiliations.

\section{Submit your manuscript to a SpringerOpen ${ }^{\circ}$ journal and benefit from:}

- Convenient online submission

- Rigorous peer review

- Open access: articles freely available online

- High visibility within the field

- Retaining the copyright to your article

Submit your next manuscript at $\boldsymbol{\nabla}$ springeropen.com 